\title{
RIF Entrevista
}

\author{
DOI - 10.5212/RIF.v.17.i39.0013
}

\section{Descolonizar o conhecimento: Entrevista com André Luis Queiróz ${ }^{1}$}

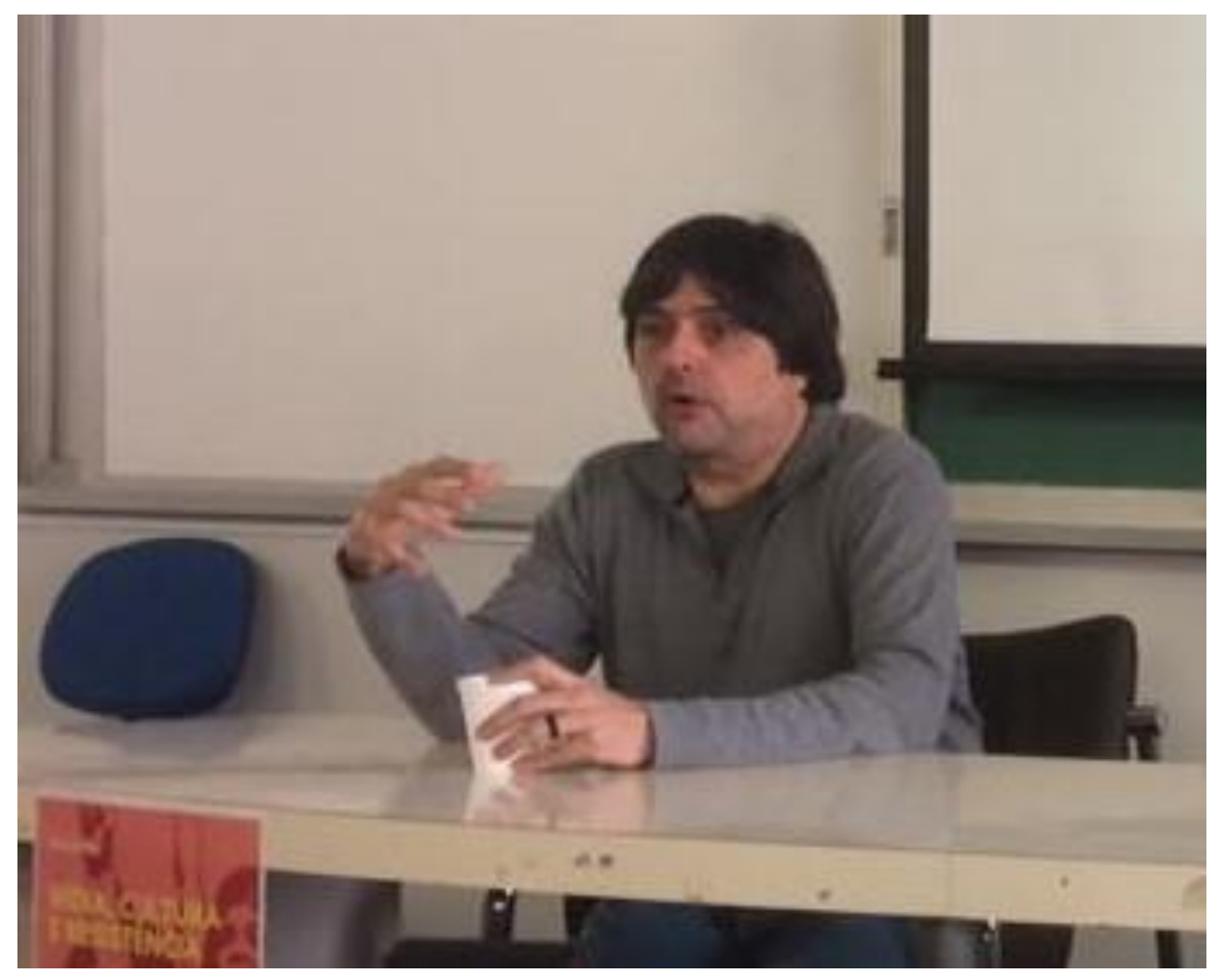

Rosangela Maria Silva Petuba ${ }^{2}$

Mariza Boscacci Marques ${ }^{3}$

Karina Janz Woitowicz ${ }^{4}$

Robson Laverdi

\footnotetext{
${ }^{1}$ Entrevista com o escritor, professor e diretor André Luis Queiróz realizada em 11 de maio de 2018 em Ponta Grossa/PR.

${ }^{2}$ Historiadora, doutora em História Cultural, professora do Curso de História da Universidade Estadual de Ponta Grossa. E-mail: rosangelapetuba@yahoo.com.br

${ }_{3}$ Professora Dra. do Curso de Engenharia Química da Universidade Estadual de Ponta Grossa. E-mail: marizabmarque@gmail.com

${ }^{4}$ Jornalista, doutora em Ciências Humanas, professora do Curso de Jornalismo e do Programa de PósGraduação em Jornalismo da Universidade Estadual de Ponta Grossa. E-mail: karinajw@gmail.com

${ }^{5}$ Historiador, doutor em História Social e pós-doutor em História Cultural, professor do Curso de História da Universidade Estadual de Ponta Grossa. E-mail: laverdirobson@gmail.com
} 


\section{RIF, Ponta Grossa/ PR Volume 17, Número 39, p.216-224, Julho/Dezembro 2019}

O professor e diretor André Luis Queiróz esteve em Ponta Grossa/PR em maio de 2018 para uma atividade correlata do Projeto de Extensão Tela Alternativa", intitulada "Cinema e Memória na América Latina" para debater sobre cinema e história brasileira e latinoamericana a partir da exibição dos filmes El Pueblo que Falta (2015) e a pré-estreia do filme Araguaya, Presente! (2018), ambos dirigidos por André Queiroz e Arthur Moura.

Escritor, ensaísta e professor do Departamento de Estudos Culturais e Mídia da Universidade Federal Fluminense, André Queiróz é doutor em Psicologia Clínica pela Pontifícia Universidade Católica de São Paulo (PUC-SP - 2000), mestre em Filosofia pela Pontifícia Universidade Católica do Rio de Janeiro (PUC-Rio - 1994) e licenciado em Filosofia pela Universidade do Estado do Rio de Janeiro (UERJ - 1989). Já escreveu diversos livros, entre eles: A Morte Falada (Ed. 7 Letras, RJ, 1998); Foucault - o paradoxo das passagens (Ed. Pazulin, RJ, 1999); e Tela Atravessada - ensaios sobre cinema e filosofia (Ed. Cejup, Belém, 2001).

A entrevista foi concebida inicialmente para ser uma conversa sobre cinema e América Latina. Contudo, o resultado desse diálogo trouxe à tona questões nas quais se conectam a trajetória pessoal e uma trama muito rica de diversos caminhos articulados inicialmente a partir de uma "relação com a palavra escrita", entretecida e amadurecida junto com a formação e atuação docente na Universidade Estadual do Rio de Janeiro. Esse diálogo não é, entretanto, fácil e cômodo, pois André tece uma crítica profunda às "baias dos especialismos" e do "produtivismo" da vida acadêmica brasileira, uma recusa consciente das "posturas" e "imposturas" desse sistema. Sua trajetória como aluno de graduação e pós-graduação, professor (inicialmente na Amazônia), escritor, ator e diretor de teatro e cinema revela uma visão aguda sobre as tramas do pensamento cindido, da recusa do interdito do pensamento colonizado, de uma "produção intelectual com obediência" (escrevência) e acima de tudo uma busca irrequieta e criativa por uma formação e uma produção acadêmica capaz de construir um outra universidade, defensável do ponto de vista social, político e intelectual, ou como diz o próprio entrevistado, a busca de uma "escritura" autônoma de si e do mundo.

\footnotetext{
${ }^{6} \mathrm{O}$ Tela Alternativa é um projeto de extensão da Universidade Estadual de Ponta Grossa e se destina à exibição e discussão de filmes com temáticas pré-definidas. $O$ projeto também propõe uma atividade de prestação de serviço voltada para os acadêmicos da UEPG e comunidade em geral, com o propósito de possibilitar uma compreensão das questões da história brasileira e latino-americana recente, ao fornecer um panorama dos fatores econômicos, socioculturais e políticos que tem moldado a realidade atual da América do Sul. O projeto, em 2018, teve como tema "sensibilidade com olhar crítico".
} 


\section{RIF, Ponta Grossa/ PR Volume 17, Número 39, p.216-224, Julho/Dezembro 2019}

Na versão da entrevista que segue, foram suprimidas informações referentes ao início da entrevista, com detalhes sobre a trajetória pessoal do professor, e destacadas as perguntas e respostas relativas à sua visão sobre o papel da Universidade e à sua atuação na (re)construção da memória na América Latina. O tom crítico das reflexões deixa evidente seu posicionamento político diante de temas necessários na atualidade, da produção cinematográfica aos desafios da vida acadêmica.

Rosângela Petuba: André, para nós uma das mais ricas características do processo de entrevista é a possibilidade de o entrevistado narrar a sua própria história. Gostaríamos de começar ouvindo um pouco sobre você, sua biografia pessoal, trajetória profissional enfim, sua história para que possamos compreender nela o lugar do qual você fala agora.

André Luis Queiróz: A coisa mais antiga que eu me lembro acerca de mim mesmo é a minha relação com a palavra, a palavra escrita. E desde muito guri sempre tive uma relação com a palavra e com o trabalho da escritura, fazia umas poesias muito toscas, muito profundamente toscas e mostrava isso. Eu me lembro que publiquei um livro que também é impronunciável e que a melhor coisa que aconteceu foi que setenta por cento da edição foi comida pelas traças literalmente. Isso poupou muita gente de ter acesso e talvez até posteriormente de usar aquilo como arma contra mim, né? Mas havia muito foco... a melhor riqueza daquilo, daquela experimentação era a riqueza do exercício com a palavra e a seriedade com que aquilo ali batia em mim. É implicava num universo de recolhimento também e eu acho que isso foi uma coisa que também marcou muito a minha formação. Eu costumo dizer que é isso é bom e ruim, não sei! Tem um lado muito ruim e tem outro lado bom assim. É se for fazer uma análise política e social do que eu vou dizer agora no âmbito particular é ruim, numa perspectiva pessoal, psicologizante eu acho que é bom porque eu fui uma figura que no meu processo de formação e, eu estou voltando lá trás, pensando quase que a infância nos primeiros anos quando começa a se perceber no mundo, é eu acho que fui uma figura que cresci pra dentro entendeu? E o que é crescer pra dentro? Crescer pra dentro é investigar a si próprio com as limitações de cavidade, né? [...]

Eu queria fazer da vida não sei o quê, queria fazer Filosofia, Teatro e não dava pra nada [risos]. [...] Ai pintou na PUC que, não sei se vocês conhecem a PUC, é uma universidade da pequena 


\section{RIF, Ponta Grossa/ PR Volume 17, Número 39, p.216-224, Julho/Dezembro 2019}

e média burguesia, né? Dependendo do curso que você faça, dali você vai pra Harvard. E depois você vem para o Ministério do Planejamento e de Economia, né? [risos]. E a Filosofia fazia com a Graduação e era uma coisa ali dentro e para eu conseguir estudar tinha aquela coisa de ter a bolsa também, mas ainda não tinha virado uma fábrica, né? Assim hiperarticulada, ainda não tinha hipertrofia nas chamadas agências de fomento, não tinha ainda isso. A UERJ continuava no primeiro tempo, por exemplo, só para fazer uma referência, não tinha pós-graduação, não falava de programa de pós-graduação que nem hoje em dia enche a boca para falar, como se fosse um distintivo de classe de prestígio de poder. Não rolava isso. Eu fui fazendo lá o Mestrado porque eu mais ou menos queria levar uma vida dentro da Universidade fazendo o que eu gostava, escrevendo e estudando também e aí eu vejo uma vez na parede estava lá: Concurso na Universidade de Santarém no Pará. Legal, eu vou! E comecei a estudar. [...] E aí enfim eu fui para lá, fiquei seis meses em Santarém e depois de lá eu migrei, tive que fazer um outro concurso pra Belém. Ali já estava entrando para o universo daquilo que seria o trabalho na Universidade em uma outra perspectiva. Eu já estou pronto como professor, eu era um menino naquela época dando aula, eu era um pouco mais velho que os estudantes. E aí termino o Mestrado, entro no Doutorado, Doutorado eu fui fazer em Psicologia Clínica que eu queria estudar - super francês né? - em terras nacionais, eu queria estudar Deleuze e Guattari. Eu queria estudar Movimento anti-manicomial e tinha uma coisa do Foucault da História da Loucura e era por aí que eu ia. Queria ser acompanhante terapêutico, queria embarcar por essa seara. Então eu fui fazer Psicologia, eu já tinha começado e abandonado o Mestrado em Psicologia e aí eu vou pra PUC de São Paulo. E aí a PUC de São Paulo é outro adendo desse universo burguês, né? [...] Só que ali já tinha o contraste com a experimentação da Amazônia. Esses desassossegos vão se dando também nesses lugares porque, de uma certa maneira, me afrontavam com a minha condição, sabe por que? Eu não era um cara que vinha daquele lugar. Aquele lugar não representava meus interesses, as minhas vontades [...].

Mas enfim ali eu estou fazendo Psicologia e vou acabar escrevendo sobre Foucault de novo. Mas aí eu já estou fazendo uma porção de outras coisas também, né? Eu já tinha aprofundado a relação com a palavra escrita, já estava escrevendo romances e publicando romances. Já estava assim transitando na seara do cinema numa perspectiva que era uma perspectiva de 


\section{RIF, Ponta Grossa/ PR Volume 17, Número 39, p.216-224, Julho/Dezembro 2019}

outro cara que virou os filmes e que tenta falar dos filmes a partir também do texto da palavra. Então eu começo a escrever sobre os meus filmes e aí começo a me autonomizar desse processo de formação. [...]

Essa desestabilização é uma desestabilização ainda limitada. Ela é limitada no mundo a partir do qual, digamos assim, a minha cerzidura intelectual e conceitual foi sendo tangida. E essa cerzidura que foi sendo tangida, era tangida no interior daquilo que seria essa escola pensamental, pensamento francês e blá, blá, blá. Então tinha uma crise, a desestabilização viabilizava outras matrizes e outras formas de conduta. Então uma das formas de conduta era mais ainda no limite do francesismo digamos assim, né? Era, por exemplo, não vou me colocar nas searas, nas correias - como que fala aquilo? - nas baias. Não vou me colocar dentro das baias do pensamento cindido. E o que seriam as baias do pensamento cindido? Dos especialismos. [...] Então, a desestabilização já me jogava pra outras searas, mas ainda assim para outras baias. E nessa ida para outras baias teve a questão da crítica literária.

A relação com a palavra é fundante [...]. Então assim, outras teceduras, outra baia absolutamente mediocrizada é o quê? É a - e aí vou usar uma expressão barthesiana escrevência acadêmica. O Barthes sempre fazia uma distinção entre escrevência e escritura. E o que é a escrevência? A escrevência é a bula de remédio. E o que é a bula de remédio? É o que se faz nos papers acadêmicos, né? É uma carrada de citações. Você tem um dispositivo de interdito, o colonialismo está aí, um dispositivo de interdito o tempo todo, você não pode avançar o rigor da referência ao texto original. [...] O perverso desse processo é que isso vira modos operantes do ensino do fazer. E aí isso passa ser o quê? Isso escolariza né? Então aí todos os estudantes eles vão sendo escolarizados nessa mediocridade da escrevência. E aí já a relação da escritura é o quê? A relação dessa escritura não é o impostoreio, a impostura da escrevência, mas a escritura justamente de você ser capaz de pegar todas essas referências e você criar alguma coisa que é totalmente distinta e que joga pra fora. [...] Eu vou perceber que a condição mesma toda ela é desestabilizada. Aí eu acho que é uma hiperpolitização dessa reflexão. Por que a condição toda é desestabilizada? Por que é a condição colonial, entende? Quer dizer onde o que cabe a nós é o quê? É a reprodução mimética e a transposição mecânica de um conceituário que não reflete, que não serve pra gente pensar e refletir e aprofundar aquilo que seria irredutível na nossa condição de latino-americanos. Então essa 


\section{RIF, Ponta Grossa/ PR Volume 17, Número 39, p.216-224, Julho/Dezembro 2019}

universidade, com esses modos operantes, com suas matrizes conceituais, com sua disponibilidade servil, com suas estruturas de funcionamento retro alimentante da condição servil, do servilismo, isso não dava! Aí eu percebo que a ficha caiu!

Karina Janz Woitowicz: Essa escrevência seria uma produção com obediência?

AQ: É mais do que obediência. É sempre obediência, mas é mais do que isso. É mais, é uma forma canônica, e interditora. É um dispositivo de interdição e de mediocratização. É uma interdição na mediocridade e aí você segue aquilo [...].

Mariza Boscacci Marques: A gente pode pensar que nos anos sessenta e oitenta foi encubado um ideal de pueblo latino americano no qual fosse possível a partir da identificação de pontos comuns no processo colonizador extrativista, escravagista que tentou apagar toda e qualquer cultura, língua e identidade, mitos e valores. $\mathrm{E}$ a partir dessa identificação ressignificar uma força que pudesse mudar o andar histórico da América Latina. A gente pode considerar que isso existiu? Agora aonde é que estão esses nós que pensaram nisso, que vivenciaram isso, lutaram por isso, o que estão fazendo agora ou não estão fazendo mais isto? Você acha que o teu cinema, essa tua linguagem do cinema com sensibilidade, com sensibilizações, com essa proposta, conseguiria atingir a geração que a gente tem hoje, na condição que a gente tem hoje?

AQ: Eu vou começar por aí e vou na direção das outras questões. Por exemplo, eu não sou uma figura de que estuda redes sociais. [...] Eu acho que isso tem uma implicação com o que você está falando, com certeza tem muito a ver mesmo. É, por exemplo, tu pensa assim: como medir essa recepção, né? Sei lá, se mede a recepção a partir do número de views, não é isso? [...] A gente fez o trailer e ai tem o negócio assim impulsionar, isso é uma merda! A gente bota uma grana e impulsiona.

[...] Produção do cinema independente é estafante. Por que você trabalha no limite das coisas porque você trabalha em todas as etapas do processo produtivo e talvez eu até me envergonharia de falar em que níveis disso, ainda que isso seja o outro lado do trabalho alienado, você tem todas as etapas da produção do sentido. Mas é estafante. $E$ aí a gente tem um monte de ideias de outros projetos, né? Por exemplo, tem o projeto de um filme que já 


\section{RIF, Ponta Grossa/ PR Volume 17, Número 39, p.216-224, Julho/Dezembro 2019}

tem um nome chamado $O$ Joio e o Trigo que a gente vai falar sobre a questão do nacionalismo crítico, Brasil, Argentina como contraponto às bandas patrióticas. É porque um dos debates que se perdeu com 68 é a ideia de pensar também a questão de nacionalismo crítico revolucionário. Porque normalmente a ideia do nacionalismo nos é impregnada sobre a ideia do modelo dos países capitalistas centrais que seria a ideia do fascismo, sendo nacionalista ou fascista. É isso é uma farsa, né? Por quê? Por que nós não somos imperialistas. Nós ficamos contra o imperialismo e a gente só pode lutar contra o imperialismo em algum momento, mesmo que a partir de um primeiro instante de uma etapa histórica a partir da defesa daquilo que é nosso. E isso implica um avançar em direção ao nacionalismo, não um nacionalismo das bandas fascistas, não tem nada a ver com isso, das bandas patrióticas, só se reconhece como nacional a camisa de seleção brasileira ou não sei o quê, não é nada disso, não tem nada a ver isso. Até mesmo porque esses que encampam esse projeto vá lá ver as suas teses, são todas teses que se coadunam com as teses do Conselho de Washington, são teses do empirismo mais absurdo. Outro projeto é fazer uma história à esquerda, crítica do processo de formação do PT. De que maneira que o PT desde o seu nascedouro, eles se enquadram dentro daquilo que seria uma espécie de preparação histórica de um projeto contrarrevolucionário. Então essa é uma segunda ideia. E uma terceira ideia que é a ideia de montar uma série, né? E essa serie se chama Vozes a Contrapelo em que cada episódio a gente vai trabalhar com um personagem. Então pegar um personagem do jornalismo, por exemplo, e não sei se vocês já ouviram falar, do Luiz Flavio Pinto, e os debates que o Luiz Flavio encapou ao longo da vida. Pegar um cara da música e aí me vem o Vintana Mil, um cara fantástico das Minas que é o Sergio Santos. Pega um pessoal do teatro, pega essa ideia de fazer uma série assim. E os livros, mas aí a gente está pensando em outra forma de produção porque uma das questões, um dos nós é o custeio da produção, né? E os livros enveredam pelo que são as vozes da Latino América e aí ir recolhendo esse material de tudo o que a gente vai colhendo, das nossas viagens e ir gerando material sobre isso. Então esse é um trabalho, o meu trabalho que por um lado só dá tempo de fazer porque eu dou aula na Universidade. Então mal ou bem tudo o que eu faço de uma certa maneira cabe dentro do trabalho da Universidade. Então obviamente só é possível fazer esse tipo de coisa que eu venho fazendo na medida que eu rompi com a pós-graduação. Não atuo mais na pós-graduação, não acho possível, agora outra 


\section{RIF, Ponta Grossa/ PR Volume 17, Número 39, p.216-224, Julho/Dezembro 2019}

vez faço minhas palavras as do Orides, não acho possível manutenção da vida inteligente se você está inserido num programa de pós-graduação, no máximo você é capaz de mobilizar as duas moléculas que ainda te restam. E porque não é possível! Não é possível assim você entra no tarefismo, no produtivismo, como seja... é uma pena que as pessoas tenham aderido a isso, mas isso acabou rolando, é uma questão, uma autocrítica que vai ser sabotada, não vai ser promovida. Essa é uma questão. E o momento de crise da Universidade, o momento de crise institucional é a medida e o momento que você avança.

Robson Laverdi: É nessa direção a minha pergunta... todos nós percebemos a necessidade da Universidade se refazer. Ela precisa se descolonizar, o pensamento precisa se descolonizar, mas ao mesmo tempo uma Universidade que precisa se descolonizar num conjunto de pressões desse neoliberalismo, como é lidar com isso, né? Dentro dessa reflexão entre romper com a pós-graduação, estou no mesmo nível, a gente não aguenta mais, e ao mesmo tempo, salvaguardar esse espaço de vida inteligente ainda que é a Universidade?

AQ: Primeiro a gente teria que avaliar se de fato isso que a gente experimenta aqui dentro é vida inteligente. Isso é um elemento, outro... porque não é porque você encontra ilhotas de sobrevivência que você pode dizer que seja estrutural. Então modo geral eu não acho que seja estrutural, a universidade embota a produção na medida em que ela submete a produção dos seus formalismos, né? É engraçado, por exemplo, tem gente que me pergunta: você já fez o projeto de pesquisa do que você está fazendo? Eu falo assim, não deu tempo cara. Eu já estou fazendo o negócio. Eu não fico fazendo pesquisa. Eu já estou fazendo a parada. Projeto de pesquisa é uma duplicidade, se quiser fazer por mim, quer fazer? Se você não fizer um projeto de pesquisa você não avança, você não avança nos editais...

[...] Como a gente pode pensar as questões de crises institucionais. As crises institucionais e os tempos de crises, se fosse falar numa terminologia filosófica, a crise é condição ontológica de produção e a condição ontológica da criação é a crise. Por que, por exemplo, se a gente não tiver em crise, você está em "love", você não questiona, agora se você está em crise as coisas todas derrapam e aí você tem que produzir algo novo. O lance é que você tem que afrontar as questões e aí a condição que você está também, a condição que te estruturou quando você 


\section{RIF, Ponta Grossa/ PR Volume 17, Número 39, p.216-224, Julho/Dezembro 2019}

aprofunda a autocrítica. O que o PCdoB escamoteou no processo de Araguaia, o que o PT escamoteia na sua própria condição. Então e nós escamoteamos porque os professores não querem pensar isso. Porque é aquela coisa é uma certa ideia de zona de conforto. O que é a zona de conforto?

[...] A zona de conforto é a baia. Então tipo assim, agora que você tem, sei lá, o seu pequeno título de posse, então você não vai questionar o sistema. Você está com o título de posse, como assim, vai questionar o sistema de propriedade se eu sou um pequeno agricultor, um pequeno agricultor entre aspas aqui, e você não quer questionar aquele trampo. Então assim, a gente está tendo a oportunidade histórica de ir além da Universidade que há. Não ir além na direção do projeto hegemônico neoliberal, até mesmo porque a Universidade que agoniza é o projeto neoliberal, Universidade neoliberal. Agora vivemos um momento da crise de acumulação do capital então há um estiramento do capital distributivo burocrático de Estado. Então o quê? Corte de verbas. E o corte de verbas é aquela coisa: tu não vais se defender mais numa Universidade neoliberal, ela é indefensável. Então que tal uma Universidade Nacional Popular, uma Universidade tem que abrir os muros dela e não é por sistema de cotas. Que o sistema de cotas você não abriu nada, o sistema de cotas na Universidade Neoliberal você abriu e bota para dentro o quê? Bota para dentro os excluídos e aí você submete ao processo de ideologização dos excluídos. Então você os prepara para ser o quê? Para se reconhecer a partir dos valores dos feitores. Mas não, essa Universidade Nacional Popular tem que se debruçar sobre as realidades reais que nos assolam. E as realidades reais que nos assolam não há nenhuma maior do que essa, nenhuma, nenhuma, me perdoem! Qualquer área que nós tivermos aqui é a nossa condição de subdesenvolvimento e a nossa condição de dependência sociável. Essa é a realidade maior que nos tange a todos. Então se a universidade não se debruçar sobre isso, ela precipita seu próprio fim e ainda te falo mais, numa boa, ela desaparece sem que as massas percebam. 